\title{
TOP-DOWN VERSUS BOTTOM-UP THEORIES OF SUBJECTIVE WELL-BEING*
}

\author{
Bruce Heady, Ruut Veenhoven \& Alex Wearing \\ Publiced in: Social Indicators Research, 1991, vol. 24. pp. 81-100
}

\begin{abstract}
This paper addresses issues of causal direction in research on subjective well being (SWB). Previous researchers have generally assumed that such variables as domain satisfactions, social support, life events, and levels of expectation and aspiration are causes of SWB. Critics have pointed out that they could just as well be consequences (Costa and McCrae, 1980, Veenhoven, 1988). In some contexts this has been referred to as the top-down versus bottom-up controversy (Diener, 1984). The main purpose is to propose a general statistical model which holds promise of resolving this controversy. The model can be used when three or more waves of panel data are available. It is used here to assess causal direction between six domain satisfactions (marriage, work, leisure, standard of living, friendship and health) and SWB. Data are drawn from four waves of an Australian Quality of Life panel survey (1981-1987) with an initial sample size of 942.
\end{abstract}

\section{INTRODUCTION}

One of the most fundamental problems in research on subjective well-being (SWB) is uncertainty about which variables cause SWB and which are consequences. Almost all previous research has been about the causes of SWB. However most of the variables described as causes have only been shown to be correlates of SWB, and might conceivably be consequences, or perhaps both causes and consequences. Diener (1984) has distinguished between bottom-up and top-down theories of SWB. Bottom-up causation is where particular variables cause SWB and top-down causation is where SWB produces certain outcomes.

Among the variables commonly treated as causes of SWB are domain satisfactions, social support, major life events and reference standards (expectations, aspirations, sense of equity etc.). Several reviewers have pointed out that all these variables could conceivably be consequences of SWB and have urged greater attention to issues of causal direction (Costa and McCrae, 1980; Diener, 1984; Veenhoven, 1984, 1987). Informally, however, there has been a tendency to dismiss these exhortations as requiring investigation of hopelessly confounded chicken-and-egg issues; 'there is no point in asking which came first the chicken or the egg'.

The main purpose of the present paper is to propose a statistical model which holds promise of resolving issues of causal direction. The model can be used if three or more waves of data are available from the same panel of respondents. The purpose of the model is to estimate the net effects of a variable of interest on SWB and of SWB on the variable. Estimated effects need to be net of spurious covariation due to possible joint dependence of both variables on other variables, whether these other variables are included in the model (which they are if measured) or omitted (if unmeasured). We shall refer to the net effect of a variable of interest on SWB as a bottom-up (BU) effect, and the net effect of SWB on the variable as a top-down (TD) effect.

This paper focuses on linkages between domain satisfactions and SWB. The six domains selected for analysis - marriage, work, material standard of living, leisure, friendship and health - have consistently been found to be strong correlates of SWB (Andrews and Withey, 1976; Argyle, 1987; Campbell, Converse and Rodgers, 1976; Headey, Holmstrom and Wearing, 1985). Most researchers have assumed that a bottom-up model is appropriate a ore precisely, thatmallimear additive combination of domain satisfactions accounts for SWB (Andrews and Withey, 1976;

Correspondence: Prof. Dr. Ruut Veenhoven Erasmus University Rotterdam, Faculty of Social Sciences, P.O.B. 17383000 DR Rotterdam, The Netherlands www2.eur.nl/fsw/research/veenhoven

Printed version: www.SpringerLink.com 
Argyle, 1987; Campbell et al., 1976; Headey et al., 1985). In other words, the whole is the sum of the parts; satisfaction with life is a result of marriage satisfaction, job satisfaction, leisure satisfaction etc. Contrary to this view, Diener (1984) notes that high intercorrelations among domain satisfactions could be taken as evidence for a top-down model. The correlations suggest that domain satisfactions could be just a spin-off from overall levels of life satisfaction. A third possibility, implied by Costa and McCrae (1980), is that apparent causal relationships between domain satisfactions and measures of SWB are spurious, with both sets of variables being dependent on stable personal traits, notably extraversion and neuroticism.

Matters become more complex when it is recognised that the three models outlined above are not mutually exclusive. To give an example, the correlation between marriage satisfaction and SWB may be partly due to the influence of marriage on life satisfaction, partly due to the influence of life on marriage, and partly spurious. Furthermore, contrary to what previous reviews have implied, there is no strong reason to expect that the same pattern of relationships holds for all domains. As will be seen, the evidence indicates that the relative strength of BU and TD effects varies from domain to domain.

This paper should be read as an exploratory analysis of two-way causation, using panel data. It is hoped that the statistical model proposed here has broad application in SWB research. However it should be emphasized that results are only as good as the statistical assumptions underlying them. It is desirable to vary assumptions to se if results are substantially affected (sensitivity analysis). Where possible, the effects of alternative assumptions have been tested in this paper and results appear not to change much. Nevertheless the model requires careful scrutiny and results need replicating before they can be accepted with confidence.

\section{METHODS}

\subsection{Sample}

Data to estimate the models come from four waves of the Australian Quality of Life Panel Study (1981, 1983, 1985, 1987). The panel study is conducted in Australia's most densely populated state, Victoria. A stratified probability sample of 942 persons was drawn in 1981. By 1987649 respondents remained. House movers are usually traced (over 350 respondents moved between 1981 and 1987) but, inevitably, panel loss is fairly substantial. Checks have shown that the means and standard deviations of all variables (except age) have remained virtually unchanged over the four waves. It is hoped that the study will continue for a decade until 1991.

\subsection{Measures}

\section{Life Satisfaction.}

It is generally agreed that at least three dimensions of SWB need to be distinguished: cognitive life satisfaction, positive affect and negative affect (Andrews and Withey, 1976; Argyle, 1987; Diener, 1984). In the present paper we focus on life satisfaction.

This was measured by Andrews and Withey's (1976) Life-as-a-whole Index. The index requires twice asking respondents, 'How do you feel about your life-as-a-whole?' The two items were approximately twenty minutes apart on the interview schedule. The response scale was a 9-point Delighted-Terrible scale, expanded from Andrews and Withey's 7-point scale to reduce bunching at the top end (Headey et al., 1984). The Life-as-a-whole Index is considered one of the most reliable and valid measures of cognitive life satisfaction (Diener, 1984; Veenhoven, 1984). The two items were included as separate indicators in our L1SREL measurement models (see below). 


\section{Domain satisfactions.}

Levels of satisfaction with the domains of marriage, work, standard or living, leisure, friendship and health were measured on a 9-point Delighted-Terrible scale. For all domains multiple items were used to enhance reliability. For inclusion in measurement models the items measuring each domain were combined into two equal sub-sets. This had the effect of producing two adequately reliable indicators, whereas inclusion of all items separately would have meant that some indicators had low reliability.

\section{Personality.}

The Eysenck Personality Inventory, Form B (Eysenck and Eysenck, 1964) measures extraversion and neuroticism. For inclusion in the measurement model the 24 indicators of extraversion were split into sub-sets of 12 , as were the 24 indicators of neuroticism.

\section{Socio-economic status.}

The three indicators were gross family income, the occupational status of the main breadwinner and the educational level of the respondent.

The other two measures included in models were sex $($ male $=1$, female $=2)$ and age. Both were assumed to be $100 \%$ reliable measurement models.

\subsection{Data Analysis: Assessing Causal Direction}

A concept of causation which statisticians often work with requires that in order to say that A causes B one has to show that:

1. A and B are correlated;

2. The correlation is not entirely spurious;

3. A precedes B in time (changes in A precede changes in B).

The biggest difficulty faced in SWB research, and survey research generally, relates to the third condition. Take the relationship between a domain satisfaction (DS) and life satisfaction (LS). In a panel survey several measures of both variables are obtained, and the scores of many respondents change. However no direct observation is possible of whether changes in DS precede or follow changes in LS. In order to get round this problem statisticians have persistently proposed methods based on the idea that if the relationship between DS1, (domain satisfaction at time 1) and LS2 (life satisfaction at time 2) is stronger than between LS1 and DS2, then the direction of causation is predominantly from DS to LS. On the other hand if LS1 $\rightarrow$ DS2 $>$ DS1 $\rightarrow$ LS2, then causation runs mainly form LS to DS.

Kessler and Greenberg (1981) in their thorough review of alternative methods based on this reasoning conclude that, if three or more waves of panel data are available, the following model is particularly promising. It is promising (a) because no instrumental variables are required (and the search for appropriate instruments is often fruitless) and (b) because few restrictive assumptions are required.

The usual problem with models which include two-way causation is that some equations are not identified (i.e. there are too many unknowns and too few pieces of information). However, as Kessler and Greenberg (1981) demonstrate, their 3-wave model is identified if one includes the 
two equality constraints show in Figure 1 LS1 $\rightarrow$ LS2 is assumed equal to LS2 $\rightarrow$ LS3 and $\mathrm{DS} 1, \rightarrow \mathrm{LS} 2$ is assumed equal to DS2 $\rightarrow$ LS3. On both theoretical and empirical grounds these assumptions appear well justified in the Australian data. Note, in particular, that correlations among variables are much the same within each wave or data (see Appendix I).

The model includes both lagged and contemporaneous links between DS and LS. The crosslagged links are in accordance with the usual understanding of causation in which causes must precede effects. The concept of contemporaneous or simultaneous causation is more problematic, because it defies the time sequence requirement.

However statisticians, especially econometricians, often include simultaneous causation in their models in situations where time sequence cannot, in practice, be directly observed, but where causal lags can be assumed to be fairly short and, certainly, shorter than the interval between observations (e.g. between surveys).

Unfortunately there is another difficulty. Although the model is in principle identified, one is likely to find that, in actually estimating equations, problems of multicollinearity are encountered. In particular, estimates of the lagged and contemporaneous effects of a predictor variable (e.g. DS1 $\rightarrow$ LS2 and DS2 $\rightarrow$ LS2) are likely to be too highly correlated to be reliable 2 ). So, in practice, in any given computer run, one is forced to drop from the model either the cross-lagged links between DS and LS or the contemporaneous, reciprocal links. All is not lost, however. Models with only lagged links and only contemporaneous links can be run consecutively. Provided that the signs of the lagged and contemporaneous estimates showing causation running from, for example, DS to LS are the same, then the two estimates may be regarded as consistent, although both will be conservative if the 'true' causal (time) lag falls between the two points of observation (cf Greenberg and Kessler, 1982). 3)

In the present paper there are perhaps reasons for believing that contemporaneous links come closer to providing accurate estimates than lagged links. On a priori grounds one might expect that, if they had any effect at all, changes in domain satisfactions would have fairly rapid effects on life satisfaction. Similarly, changes in life satisfaction might be expected soon to affect domain satisfactions. At a more practical level it should be noted that interviews in the Australian panel study are conducted at two year intervals. It seems most unlikely that the causal effects analysed here take anything like two years to be felt. Supporting this view is the fact that contemporaneous correlations in the data are somewhat higher than lagged correlations (Appendix 1). In practice we shall rely primarily on contemporaneous estimates of reciprocal causation. We will find, however, that the lagged estimates not only have the same signs as contemporaneous estimates but are not a great deal lower.

The general model used to obtain results given in this paper embodies several modifications of Kessler and Greenberg's model. Five separate sets of equalities were imposed. They reflect a theory that the 'true' relationships in the structural (causal) model should be the same in all four waves of data. Technically the effect of the equalities was to assist with identification problems and to provide extra degrees of freedom in arriving at maximum likelihood estimates (see below). Two features of the model were included to test hypotheses about the possible spuriousness of links between domain satisfactions and LS (i.e. their joint dependence on other variables). Five stable personal characteristics - sex, age, socio-economic status, extraversion and neuroticism were included as exogenous variables. The first three may be regarded as standard background variables which need to be routinely 'controlled', while extraversion and neuroticism were 
included because Costa and McCrae (1980) hypothesize that apparent causal relationships between DS and LS are spurious due to these personality traits which they, among others, have shown to be very stable over a lifetime. Exogenous variables are of course assumed to be causes not consequences of DS and LS, and in so far as relationships between DS and LS are due to joint dependence on exogenous variables, the model allows these effects to be partialled out, providing a more accurate estimate of the BU and TD effects of chief interest. It should be noted that only time 1 (1981) measures of these stable exogenous variables have been included. 4) They are assumed to be related directly to DS and LS only at time 1. (However if direct links to later measures of DS and LS are inserted, then bottom-up and top-down results of main interest are virtually unaffected).

Spuriousness could also be due to variables omitted from the model. The effects of such variables are obtained by estimating correlations between error terms of equations for $D S$ and $L S$ (Kessler and Greenberg, 1981). (The correlated errors are labeled $=5$ in Fig. 2).

It needs to be recognised that, in estimating a model of this kind, we are assuming that relationships among variables are in equilibrium. If the equilibrium assumption were not met, it would be inappropriate to use structural equation methods (Kenny, 1979; Rogosa et al, 1982; Rogosa and Willett, 1985). In regard to the present model, the reader is asked to inspect the correlations, means and standard deviations in Appendix I to confirm that relationships across waves appear to be very close to equilibrium. (Appendix I covers only one application of the model. Relevant statistics for other applications are available from the authors).

To summarize: the chief purpose of the model is to estimate the effects of variables of interest on SWB and vice-versa. For reasons given, we treat contemporaneous reciprocal estimates as the best available, calculating lagged estimates primarily to check that the signs of the coefficients are the same. Spurious effects due to both included and omitted exogenous variables are also estimated in order to get more accurate estimates of the net effects of variables of interest on SWB and vice-versa. 5) Problems of identification have been dealt with primarily by imposing equalities which seem justified on grounds of theory.

\subsection{The Measurement Model}

The previous section dealt with possible relationships in a structural equation or causal model. It is also necessary to provide a measurement model; a model specifying linkages between underlying concepts and the survey items used to measure concepts. Whenever the same variables are measured at successive time points, there is a risk of misestimating relationships due to measurement errors made on the first occasion being repeated on later occasions. However, provided that there are at least two indicators for each concept, autocorrelated error can be estimated if three or more waves of data are available (Kessler and Greenberg, 1931). In the measurement model which accompanied the structural model, autocorrelated error terms were estimated whenever the same indicator (survey question) was repeatedly used to measure the same concept. We thus allowed for the possibility of first, second and third order autocorrelated error. Furthermore, error terms relating to the same indicator were constrained to be equal, because it is reasonable to assume that the degree of error would be the same on each occasion (i.e. we assumed first, second and third order methods effects; see Andrews and Withey, 1976). Details are given in Appendix II. 


\section{LISREL}

The ideal software for present purposes is LISREL IV (Joreskog and Sorbom, 1978). 6) LISREL first estimates a measurement model in order to calculate disattenuated (estimated 'true') correlations among the concepts in the structural model. It then uses these correlations to calculate the coefficients in the causal model (maximum likelihood estimates).

LISREL has the flexibility to perform the tasks needed to estimate our models. It can accept equality constraints, it can estimate correlations among error terms in the structural model, and it can estimate autocorrelated error in the measurement model.

The LISREL runs for this paper were based on correlation matrices and, in presenting results, standardized (not metric) maximum likelihood estimates are given. The use of standardized estimates is often considered appropriate when, as is the case here, all variables of interest have arbitrary metrics. The use of standardized estimates makes it easy to assess the relative magnitude of $B U$ and $T D$ effects, since estimates are constrained to fall between -1 and +1 . It should be noted, however, that all models were re-run using variance-covariance matrices as inputs into LISREL in order to obtain metric (unstandardized) estimates. In all cases the metric results told essentially the same story as the standardized results given below.

\section{RESULTS}

As noted above, most previous researchers have assumed but not demonstrated that a bottom-up model adequately summarizes relationships between domain satisfactions and life satisfaction. A more complicated picture emerges from the following pages. Of the six major life domains analyzed, there is one case of reciprocal causation, three of (mainly) top-down causation and two of spuriousness.

We first give results relating to marriage satisfaction and life satisfaction.

The model indicates two-way causation. Being happily married increases one's life satisfaction $(B U=0.18)$, but it is also true that happy people are move likely to maintain happy marriages ... while miserable people tend to have miserable marriages $(T D=0.12)$. No statistically significant differences were found between results for men and women.

It should be remembered that these statistically significant $B U$ and $T D$ coefficients are net of the effects of the stable personal characteristics included in the model, and of the effects of omitted exogenous variables (estimated at (0.10). Costa and McCrae's (1980) hypothesis that stable personal characteristics account for apparent causal relationships between domain satisfactions and life satisfaction appears incorrect in regard to the marriage domain.

It is essential to check that the lagged $B U$ and $T D$ estimates have the same signs as the contemporaneous estimates. For this model the lagged $R U$ estimate was 0.08 and the lagged $T D$ estimate was 0.07 (both coefficients are just significant at the 0.05 level). For reasons given above, it seems likely that the contemporaneous estimates are closer to being accurate. 7)

Since this is the first set of results presented, a number of technical points need to be made; points which also apply to subsequent models. An initial comment is that the model fits the data very satisfactory.

LISREL models can be evaluated by several measures of fit. For this model Chi-square divided by degrees of freedom was 1.60 (Carmines and McIver, 1981), Hoelter's (1983) Critical Number $(C N)$ was 258.62, and the mean absolute residual was 0.04 . It should also be noted that the standard errors and LISREL diagnostics relating to correlations among parameter estimates indicated no symptoms of multicollinearity. 
A number of sensitivity analyses indicate that reasonable variations in model specification do not affect the basic result that marriage satisfaction influences life satisfaction and vice-versa. If the correlated error terms are dropped (the terms marked $=5$ in Fig. 2), the betas change to $B U=$ 0.25 and $T D=0.20$. A valuable check, available with four waves of panel data (Kessler and Greenberg, 1981), is to remove one pair of equality constraints between MS and LS and to see if the estimates for the free parameters are approximately the same as for the constrained parameters. In fact they are $(R U=0.14, T D=0.15)$. A further possibility is to allow the exogenous variables to affect marriage and life satisfaction at all later time point as well as at time 1. Again, the reciprocal causation results of chief interest are scarcely affected. (It may be noted that, because of the large number of imposed equality constraints, the model is still identified.)

Next, how is life satisfaction linked to job satisfaction and material standard of living? A well established but puzzling finding is that most people, even those in low status and routine jobs, report fairly high levels of job satisfaction and satisfaction with their standard of living. Our panel data show that satisfaction with work and standard of living are just a spin-of (consequences) of life satisfaction and have no causal effect at all. The contemporaneous estimates (lagged estimates in parentheses) were:

$$
\begin{array}{ll}
\text { Job satisfaction } & R U=-0.07 \mathrm{~ns}(-0.03 \mathrm{~ns}) \\
& T D=-0.24(0.19) \\
\text { Standard of living satisfaction } & B U=-0.04 \mathrm{~ns}(-0.02 \mathrm{~ns}) \\
& T D=-0.18(0.12)
\end{array}
$$

It is well known from much previous research that low status people in Western countries are not much less satisfied with their lives-as-a-whole than high status people (Veenhoven, 1984). In view of the results just given, it seems that this is the main reason for them not being much less satisfied than others with their work and living standards.

Now leisure satisfaction. A surprising finding in previous research is that leisure satisfaction correlates as highly if not more highly with life satisfaction than any other domain (Andrews and Withey, 1976; Campbell et al., 1976; Headey et al., 1985). In a bottom-up framework this result is puzzling because one would not, on a priori grounds, be inclined to accept that leisure mattered most to life satisfaction. Application of the reciprocal causation model helps to resolve the puzzle because it transpires that the bottom-up link is insignificant ( $B U=0.06 \mathrm{~ns})$, whereas the top-down link is moderately strong $(T D=0.17)$. The effect of omitted exogenous variables, given by the correlated error term (marked as $=5$ in Fig. 2) is also strong (0.24). The equivalent lagged estimates confirm this pattern of results: $B U=-0.05 \mathrm{~ns}, T D=0.12$. In short, the high correlations between leisure and life satisfaction, reported in previous studies, appear to have led to inappropriate causal inferences. Leisure satisfaction is partly just a spin-off of SWB, and the relationship is partly spurious.

Several studies have concluded that satisfaction with friendships and social support are a major determinant of SWB (Argyle, 1987). But results from our model, giving contemporaneous links, show that neither bottom-up nor top-down links between friendship satisfaction and life satisfaction are statistically significant at the 0.05 level $(B U=-0.01 \mathrm{~ns}, T D=0.06 \mathrm{~ns})$. The equivalent lagged estimates were $B U=-0.01 \mathrm{~ns}$, and $\mathrm{TD}=0.04 \mathrm{~ns}$. In other words the 
correlation between friendship satisfaction and life satisfaction $(\mathrm{r}=0.49)$ appears to be spurious. The main explanation for this result is that the model includes extraversion as an exogenous variable antecedent to both friendship and life satisfaction. This causal ordering, while hopefully justified, means that, in effect, extraversion is permitted to account for as much variance as possible before the reciprocal effects of friendship and life satisfaction on each other are assessed. Extraversion is highly related to friendship satisfaction (Beta $=0.52)$ and fairly highly to life satisfaction $($ Beta $=(0.36)$, so the consequences of assumptions about causal ordering are non-trivial. The friendship domain is one in which Costa and McCrae's spuriousness hypothesis is partly confirmed.

Finally, health. The panel survey includes measures of self-reported health and health satisfaction but provides no independent medical checks. Application of the standard model indicates no significant links from health satisfaction to life satisfaction or vice-versa. The association between the variables $(r=0.36)$ is spurious, with extraversion and neuroticism being related to both, neuroticism particularly to health (dis)satisfaction. Health, then, is a second domain in which Costa and McCrae's spuriousness hypothesis is confirmed.

Table I summarizes contemporaneous and lagged estimates between life satisfaction and the six domain satisfactions considered in this paper.

It can be seen that all pairs of contemporaneous and lagged estimates have the same signs and, indeed, that the magnitudes of most pairs are similar. Substantively, this means that reasonable confidence can be placed in our interpretation of the relative importance of $B U$ and $T D$ effects.

\section{DISCUSSION}

The main purpose of this paper has been to present a general statistical model which may help to clarify issues of causal direction in SWB research. Because the model embodies numerous nonobvious assumptions, it is important to vary assumptions and check if results are substantially affected. It is also important to see if results replicate in other data sets. However if the results in this paper are confirmed, they stand a good deal of conventional wisdom on its head. Most researchers have held a bottom-up view of links between domain satisfactions and life satisfaction. Even those who have recognised the possibility of top-down causation have tended to pose the issue in either-or terms; either all relationships must be top-down or all bottom-up. The results given above paint a more complicated picture. The marriage domain is characterized by two-way causation. The work, leisure and standard of living domains show top-down causation, and the observed correlations between life satisfaction and both friendship and health satisfaction appear to be spurious. These results hold under a variety of assumptions, although not in most cases if we (misguidedly?) drop the assumption that relationships could be wholly or partly spurious (i.e. dropping the correlated error terms in Fig. 2 does make a difference).

The implications of the unexpected degree of support for top-down theory need to be carefully considered. Some might infer that the results lend support to the view that life satisfaction (or, more generally, SWB) is a fairly stable trait rather than a fluctuating state (Diener, 1984). While not directly dissenting from this interpretation, our view is that the state-trait controversy applied to SWB research offers few insights. We have estimated the stability of SWB measures at around $0.55-0.60$ for two, four and six year intervals (Headey and Wearing, 1989). This may be 
regarded as a fairly high degree of stability, but it is also true that about a quarter of the population shift by over a standard deviation in these time periods.

In future work the intention is to apply the same approach to analyzing causal relationships between SWB and other variables besides domain satisfactions. As noted above, it is open to question whether variables like social support, levels of expectation and aspiration, perceptions of role performance and reports of life events are causes or consequences of SWB ... or whether, indeed, apparent relationships are spurious. It will also be desirable to extend the analysis to other dimensions of SWB besides cognitive life satisfaction. Top-down and bottom-up theories of SWB are likely to remain in contention for the foreseeable future. In this paper we have proposed a statistical model which, it is hoped, offers promise of disentangling the causal network.

\section{Structural Equations Model}

One matrix in the structural equations model could not conveniently be printed in Fig. 3. This is the matrix of correlations among exogenous concepts.

Correlations among exogenous concepts

(1)

(2)

(3)

(4)

(5)

Sex (1)

Age (2)

SES (3)

1.00

0.08

$-0.16$

Extraversion (4) 0.03

Neuroticism (5) 0.19
1.00

0.00

$-0.26$

$-0.11$
1.00

0.09

1.00

$-0.39 \quad-0.25$

\section{NOTES}

* We particularly thank Ronald C. Kessler of the University of Michigan for his advice on statistical issues. We are also very grateful for comments from Frank M. Andrews of the University of Michigan and Mariah Evans and Jonathan Kelley of Australian National University.

Constructive Comments from an anonymous SIR reader also led to significant revisions.

1 If more equality constraints are imposed, then over-identified equations result. This is highly desirable for estimation purposes.

2 This occurs whenever the model is nearly in equilibrium (i.e. when correlations among variables in successive waves of data are approximately the same). The effect is the same as under-identification; successive waves are not supplying new information.

3 Greenberg and Kessler (1982) state that the correct estimate must be between the lagged and contemporaneous estimates. We are grateful to Frank M. Andrews of the University of Michigan for the observation made in the text. 
4 It appears odd to refer to age as a stable variable. However the relative ages of Australian panel members have of course remained entirely stable and this is what matters for the structural equation modelling which follows. Of the other exogenous variables, sex and SES are clearly stable over a 6-year period.

The personality traits, extraversion and neuroticism, have been shown to be highly stable in much previous work (e.g. Costa and McCrae, 1984). In the present study both traits have been almost $100 \%$ stable,

5 In other words the covariance between a variable of interest and SWB is treated as having four components: (1) the effect of the variable on SWB (2) the effect of SWB on the variable (3) joint dependence on exogenous variables included in the model and (4) joint dependence on omitted exogenous variables.

6 LISREL IV is preferable to later versions of LISREL. Kessler and Greenberg's 1981 demonstration that their 3-wave model is identified refers to the reduced form of the structural equations (not to the structural equations as such) and these are employed in LISREL IV. Later versions of LISREL directly estimate the structural equations.

7 It may also be noted that LISREL diagnoses less satisfactory fits between model and data when lagged estimates are used. For discussion of the measures of fit employed see p. 91.

\section{REFERENCES}

Andrews, F. M. and Withey, S. B. (1976), Social Indicators of Well-Being

Plenum, New York.

Argyle, M. (1987), the Psychology of Happiness

Methuen, London.

Bradburn, N. M. (1969),

The Structure of Psychological Well-Being

Aldine, Chicago.

Campbell, A., Converse, P. F. and Rodgers, W. R. (1976),

The Quality of American Life

Sage, New York

Cartmines, E. G, and Melver, J. P. (1981).

Analysing models with unobserved variables,

in G. W. Bohrnstedt, and E. F. Borgatta (eds.), Social Measurement: Current Issues (Beverley Hills, Sage).

Costa, P. T. and McCrae, R. R. (1980),

Influence of extraversion and neuroticism on subjective well-being, Journal of Personality and Social Psychology 38, 668-78. 
Costa, P. T. and McCrae, R. R. (1984),

Personality as a lifelong determinant of well-being,

in C, Malatesta and C. Izard (eds.). Affective Processes in Adult Development and Aging (Beverley Hills, Sage).

Diener, F. (1984).

Subjective well-being.

Psychological Bulletin 95, 542-75.

Eysenck, H. J. and Eysenck, S. B. G. (1964),

Manual of the Eysenck Personality Inventory

Hodder and Stoughton, London.

Greenberg. D. F. and Kessler, R. C. (1982),

Equilibrium and identification in linear panel models,

Sociological Methods and Research 10, 435 - 51.

Headey, B. W., Holmstrom, E. L. and Wearing, A. J. (1985),

Models of well-being and ill-being,

Social Indicators Research 17, 211 - 34.

Headey, B. W. and Wearing, A. J.(1988).

The sense of relative superiority: central to well-being.

Social Indicators Research 20, pp. 497-516.

Headey, B. W. and Wearing, A. J. (1990).

What Makes for Happiness? A Theory of Subjective Well- Being

(forthcoming).

Hoelter, J. W. (1983).

The analysis of covariance structure,

Sociological Methods and Research 11, 325 - 44.

Joreskog, K. G. and Sorbom, D. (1978),

LISREL IV

International Educational Services, Chicago.

Kenny, D, A.(1979),

Correlation and Causality

Wiley, New York.

Kessler, R. C. and Greenberg. D. F.(1981)

Linear Panel Analysis

Academic Press, New York. 
Kohn, M. L. and Schooler, C. (1983),

Work and Personality

Ablex, Norwood. N.J..

Rogosa, D. R., Brandt, D. and Zimowski, M. (1982)

A growth curve approach to the measurement of change.

Psychological Bullettin 90, 726 - 48.

Rogosa, B. R. and Willet, J. B. (1985)

Understanding correlates of change by modeling individual differences in growth.

Psychometrika 50, 203 - 28.

Veenhoven, R. (1984),

Conditions of Happiness

Reidel, Dordrecht.

Veenhoven, R. (1988),

The utility of happiness,

Social Indicators Research 20, 333 - 54. 


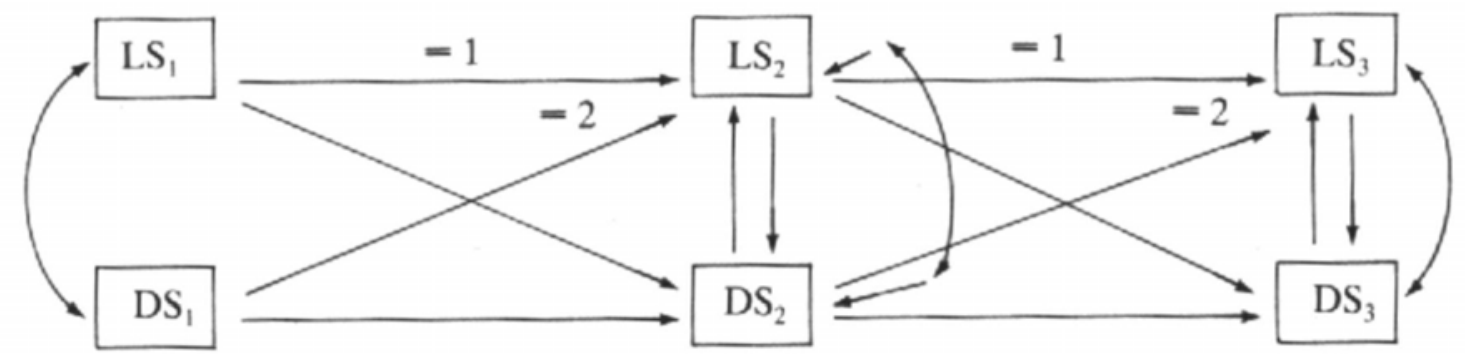

Key:

DS $=$ Domain satisfaction

LS $=$ Life satisfaction

$1,2,3=$ time points

$=1$ an imposed equality

$=2$ an imposed equality

Fig. 1. Kessler and Greenberg's three-wave model with two imposed equalities. 
$1981^{a}$

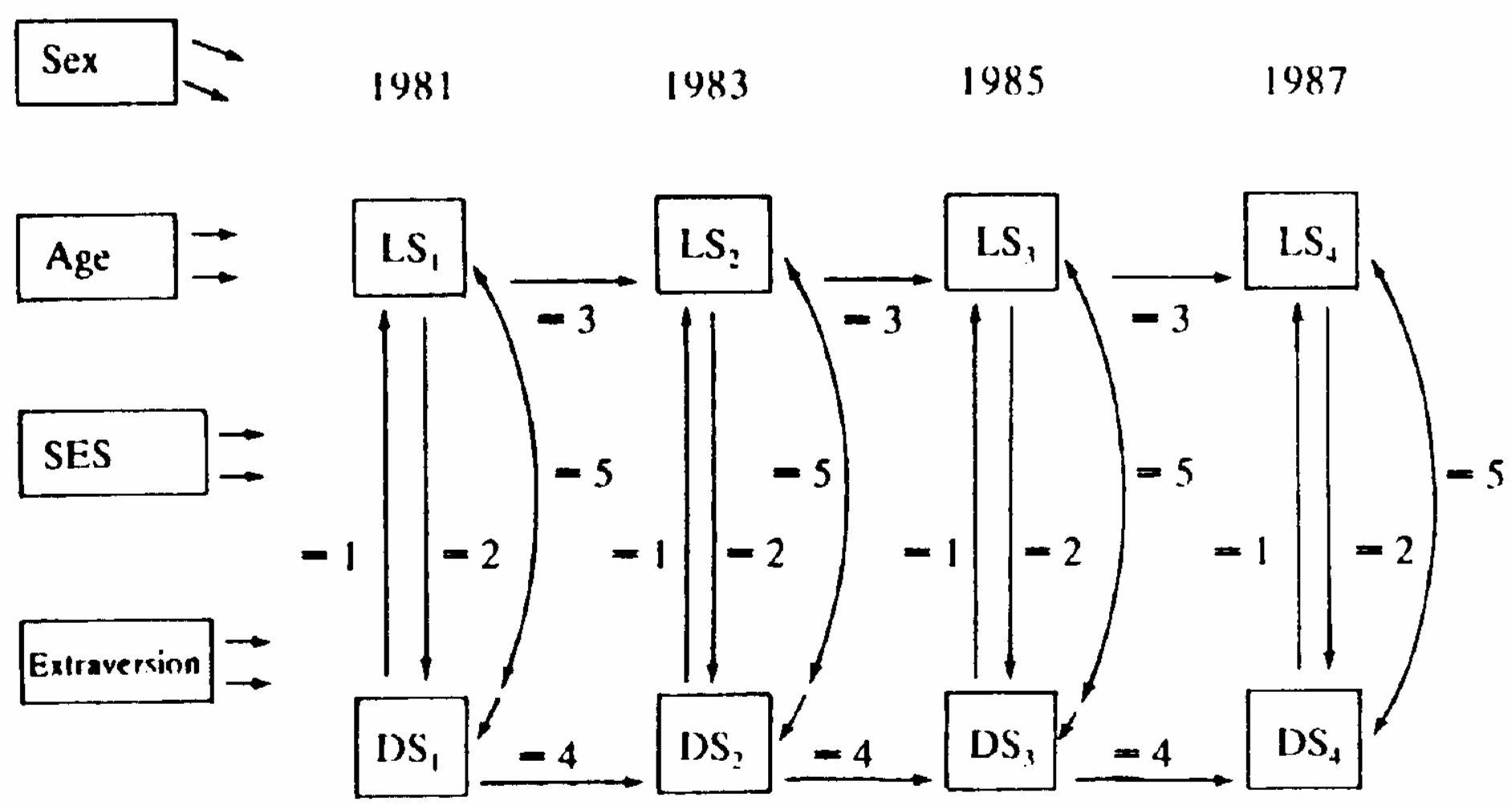

Neurnticism

KEY: see figure 1 .

a. These variables are directly linked $10 D S$ and $L S$ only at time 1 (1981)

Fig. 2. General model with 4 waves of data. 


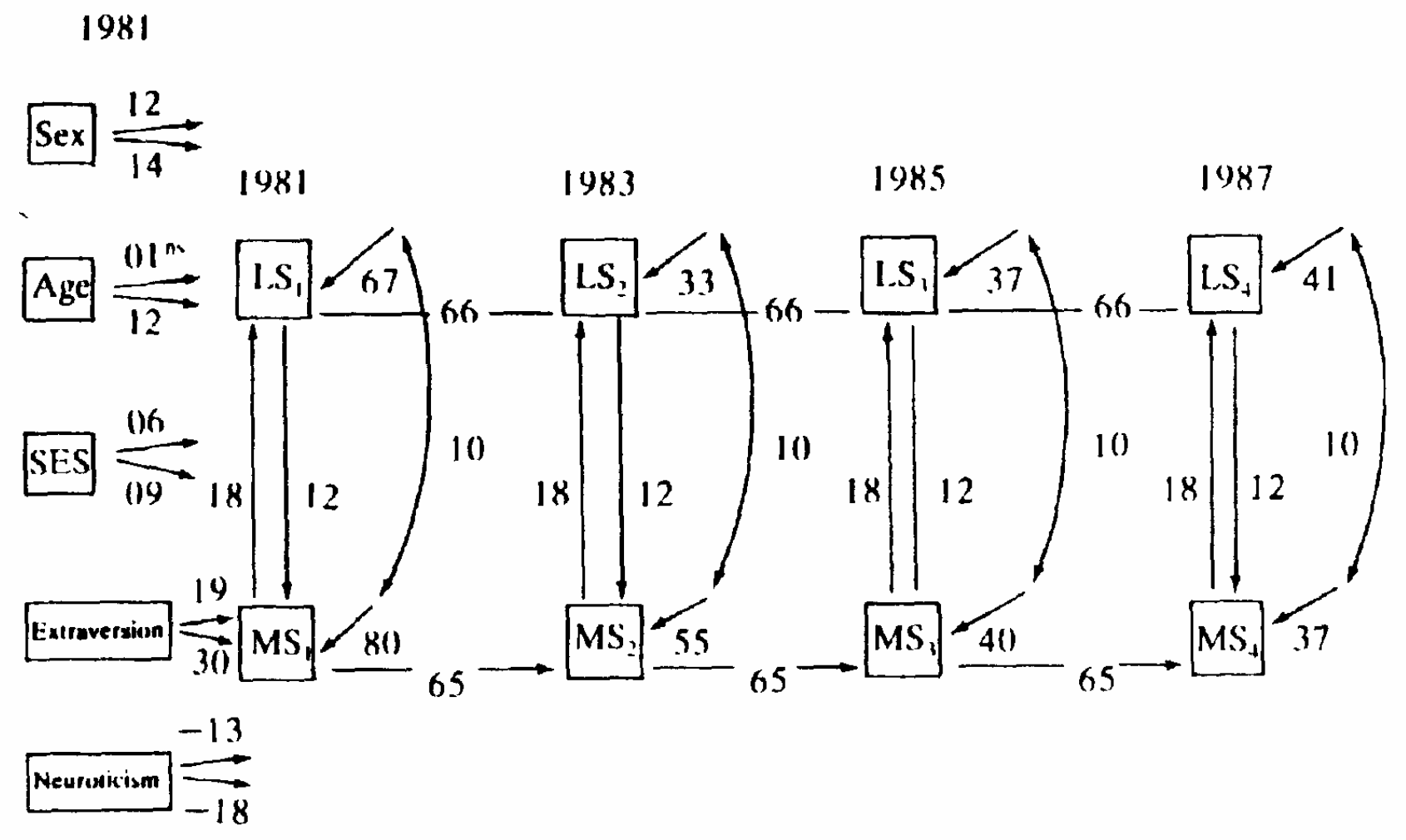

Key: MS - marriage satisfaction LS = life satisfaction

$$
\begin{aligned}
& \text { Measures of fit: } \mathrm{Chi}_{\mathrm{df}}{ }^{2}-\begin{array}{c}
395.94 \\
248
\end{array}
\end{aligned}
$$

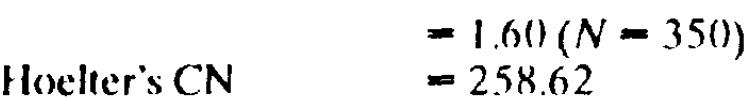

$$
\begin{aligned}
& \text { mean absolute residual }=0.04
\end{aligned}
$$

Fig. 3. Does marriage satisfaction cause life satisfaction, or vice-versa, or both? 
TABI.E I

Contemporaneous and lagged reciprocal relationships between domain satisfactions and life satisfaction

\begin{tabular}{|c|c|c|c|}
\hline \multirow[b]{2}{*}{ Domain } & \multicolumn{3}{|c|}{ Relationship with Life Satisfaction } \\
\hline & Type of Effect & $\begin{array}{l}\text { Contemporaneous } \\
\text { Effects }\end{array}$ & $\begin{array}{l}\text { Lagged } \\
\text { Effects }\end{array}$ \\
\hline Marriage & $\begin{array}{l}B U \\
T D\end{array}$ & $\begin{array}{l}0.18 \\
0.12\end{array}$ & $\begin{array}{l}0.08 \\
0.07\end{array}$ \\
\hline Job & $\begin{array}{l}B U \\
T D\end{array}$ & $\begin{array}{c}-0.07^{\mathrm{m}} \\
0.24\end{array}$ & $\begin{array}{l}-0.03^{n c} \\
0.19^{\circ}\end{array}$ \\
\hline $\begin{array}{l}\text { Standard of } \\
\text { Living }\end{array}$ & $\begin{array}{l}B U \\
T D\end{array}$ & $\begin{array}{l}-0.04^{n s} \\
0.18\end{array}$ & $\begin{array}{l}-0.02^{n} \\
0.12\end{array}$ \\
\hline Leisure & $\begin{array}{l}B U \\
T D\end{array}$ & $\begin{array}{c}-0.06^{m} \\
0.17\end{array}$ & $\begin{array}{l}-0.05^{n} \\
0.12\end{array}$ \\
\hline Friendship & $\begin{array}{l}B U \\
T D\end{array}$ & $\begin{array}{l}-0.011^{m} \\
0.06^{n+}\end{array}$ & $\begin{array}{l}-0.011^{n-} \\
0.04^{n-}\end{array}$ \\
\hline Health & $\begin{array}{l}B U \\
T l\end{array}$ & $\begin{array}{l}0.02^{\mathrm{ns}} \\
0.05^{\mathrm{ns}}\end{array}$ & $\begin{array}{l}0.00^{\mathrm{n}} \\
0.05^{\mathrm{m}}\end{array}$ \\
\hline
\end{tabular}

- Standardized maximum likelihood estimates (betas).

- $B U$ - bottom-up effects; $T D=$ top-down effects.

"Not significant at the 0.05 level. 
APPENDIX I

Means. SDs and correlations for variables in Fig. 3

\begin{tabular}{|c|c|c|c|c|c|c|c|c|c|c|}
\hline \multicolumn{11}{|c|}{ Matrix fo be analyzed } \\
\hline & I & 2 & 3 & 4 & 5 & 6 & 7 & 8 & 9 & 10 \\
\hline 1 & 1.000 & & & & & & & & & \\
\hline 2 & 0.821 & $1.0(0)$ & & & & & & & & \\
\hline 3 & 0.467 & 0.502 & $1 .(10) 0$ & & & & & & & \\
\hline 4 & 0.418 & 0.484 & 0.682 & 1.00100 & & & & & & \\
\hline 5 & 0.520 & 0.463 & 0.299 & 0.311 & 1.000 & & & & & \\
\hline 6 & 0.493 & 0.528 & 0.311 & 0.324 & 0.875 & 1.000 & & & & \\
\hline 7 & 0.325 & 0.412 & 0.515 & 0.538 & 0.491 & 0.541 & 1.0000 & & & \\
\hline 8 & 0.356 & 0.414 & 0.512 & 0.578 & 0.465 & (1).530 & 0.696 & 1.0000 & & \\
\hline 9 & 0.498 & 0.427 & 0.257 & 0.330 & 0.605 & 0.618 & 0.359 & $0 . .371$ & I.000 & \\
\hline 10 & 0.428 & 0.450 & 0.286 & 0.36 .3 & 0.571 & 0.671 & 0.423 & 0.463 & 0.838 & 1.000 \\
\hline 11 & 0.245 & 0.274 & 0.367 & 0.373 & 0.317 & 0.357 & 0.499 & 0.481 & 0.414 & 0.48 .3 \\
\hline 12 & 0.314 & 0.379 & 0.407 & 0.518 & 0.353 & 0.429 & 0.516 & 0.592 & 0.485 & 0.564 \\
\hline 13 & 0.462 & 0.436 & 0.247 & 0.329 & 0.527 & 0.549 & 0.323 & 0.361 & 0.730 & 0.700 \\
\hline 14 & 0.430 & 0.481 & 0.277 & 0.365 & 0.519 & $(1.60) 9$ & 0.338 & 0.385 & 0.670 & 0.732 \\
\hline 15 & 0.269 & 0.345 & 0.362 & 0.422 & 0.333 & 0.384 & 0.461 & 0.473 & 0.407 & 0.466 \\
\hline 16 & 0.286 & 0.390 & 0.351 & 0.461 & 0.283 & 0.337 & 0.402 & 0.480 & 01.422 & 0.498 \\
\hline 17 & 0.062 & 0.0197 & 0.089 & 0.1019 & 0.0106 & 0.073 & $0.0 \times()$ & 0.015 .3 & 0.1192 & 0.130 \\
\hline 18 & 0.005 & -0.025 & 0.111 & 0.1122 & $-(1.010 .3$ & (1). (1) 4.3 & 0.050 & -0.0 .39 & 0.0 .37 & 0.06 .3 \\
\hline 19 & 0.151 & 0.115 & 0.161 & (1.082 & 0.138 & 0.08 .3 & 0.145 & 0.108 & 0.072 & (1.026 \\
\hline 20 & 0.060 & 0.1149 & 0.124 & 0.104 & 0.089 & 0.057 & 0.111 & 0.033 & 0.121 & 0.094 \\
\hline 21 & 0.1192 & 0.0157 & $-11.11(12$ & $-(1.0)(1)$ & 0.061 & -0.0111 & -0.050 & $-(1.0(1) 0$ & $(1) .0 .33$ & $-(0.0(1) 7$ \\
\hline 22 & 0.0 .54 & 0.125 & 0.10 .5 & 0.164 & 0.065 & 0.0 .30 & 0.116 & 0.11 .5 & 0.059 & 0.07 .3 \\
\hline 23 & 0.20 .3 & 0.186 & 0.235 & (1).202 & 0.108 & 0.053 & 0.174 & 0.154 & 0.40 & 0.018 .5 \\
\hline 24 & -0.180 & -0.145 & -10.223 & -0.201 & -0.24 .3 & -0.202 & -10.197 & -0.1 .56 & -0.196 & -0.106 \\
\hline 25 & -0.190 & -0.184 & -0.238 & $-01.2 ! 2$ & -11.201 & -0.184 & -0.175 & -11.162 & -11.200 & -0.182 \\
\hline
\end{tabular}


APPENDIX I Continued

Matrix to be analyad

$\begin{array}{llllllllll}11 & 12 & 13 & 14 & 15 & 16 & 17 & 18 & 19 & 20\end{array}$

\begin{tabular}{|c|c|c|c|c|c|}
\hline \multirow{2}{*}{\multicolumn{6}{|c|}{$11 \quad 1.000$}} \\
\hline & & & & & \\
\hline 12 & 0.68 .5 & 1.000 & & & \\
\hline 13 & 0.298 & 0.406 & $1.0(1) 0$ & & \\
\hline 14 & 0.386 & 0.485 & 0.877 & 1.000 & \\
\hline 15 & 0.503 & 0.586 & 0.405 & 0.446 & 1.000 \\
\hline 16 & 0.478 & 0.62 .3 & 0.479 & $(1.5 .30$ & 0.720 \\
\hline 17 & 0.108 & 0.127 & 0.096 & 0.13 .5 & 0.0 .56 \\
\hline 18 & 0.019 & 0.025 & 0.75 & 0.8 .5 & 0.01 .34 \\
\hline 19 & 0.065 & 0.015 & 0.046 & -0.006 & 0.063 \\
\hline 20 & 0.110 & 0.066 & 0.114 & $(0.04 .3$ & 0.055 \\
\hline 21 & 0.022 & -0.008 & 0.029 & -0.0 .33 & -0.01 .3 \\
\hline 22 & 0.116 & 0.140 & 0.0 .53 & 0.078 & 0.084 \\
\hline 23 & 0.083 & 0.1 .55 & 0.010 & 0.042 & 0.147 \\
\hline 24 & -0.179 & -0.137 & -0.179 & $-1) .159$ & -0.206 \\
\hline 25 & -0.14 .5 & -0.119 & $-(0.190$ & -11.152 & -0.175 \\
\hline & $1 \times$ & analy & & & \\
\hline & 21 & 22 & 23 & 24 & 25 \\
\hline & 1.000 & & & & \\
\hline 22 & -0.061 & 1.000 & & & \\
\hline 23 & 0.0 .38 & 0.419 & 1.000 & & \\
\hline 24 & -0.2 .31 & -0.105 & $-(1.223$ & 1.000 & \\
\hline$i$ & -0.20 .5 & -0.035 & -0.204 & 0.750 & 1.000 \\
\hline
\end{tabular}

\section{Key to variables}

(1) Marriage

(2) Satisfaction

(3) Life

(4) Satisfaction

(5) Marriage

(6) Satisfaction

(7) Life

(8) Satisfaction

(9) Marriage

(I0) Satisfaction

(II) Life

(12) Satisfaction

(13) Marriage

(14) Satisfaction
$\hat{X} \quad(S D)$

$7.1 \quad(1.6)$

$81 \quad 7.5 \quad(1.2)$

$7.1 \quad(1.3)$

817.1

(1.2)

7.1

$83 \quad 7.5$

(1.4)

(1.2)

7.1

$83 \quad 7.0$

7.2

(1.2)

(1.5)

(1.3)

(1.2)

$7.1 \quad(1.1)$

(1.1)

7.0

87
1.000

$0.064 \quad 1.000$

$\begin{array}{llll}0.012 & 0.074 & 1.000\end{array}$

$0.047-0.170-0.031 \quad 1.000$

$\begin{array}{lllll}0.052 & -0.025 & 0.08 .3 & 0.482 & 1.000\end{array}$

$\begin{array}{llll}-0.054-0.1(14 & -0.099 & 0.298 & 0.318\end{array}$

$\begin{array}{lllll}0.140 & 0.028 & -0.274 & 0.039 & 0.032\end{array}$

$\begin{array}{lllll}0.106 & 0.004 & -0.051 & 0.056 & 0.097\end{array}$

$0.201-0.0150-0.208-0.231$

$0.126-0.154-0.198-0.236$ 
APPENDIX II

Measurement model for figure 3

\begin{tabular}{|c|c|c|}
\hline $\begin{array}{l}\text { Londings for indicators } \\
\text { of endogetnows conceprs }\end{array}$ & $\begin{array}{l}\text { Error serm of } \\
\text { endogenous indicalors }\end{array}$ & $\begin{array}{l}\text { Auto-correlated } \\
\text { error }\end{array}$ \\
\hline 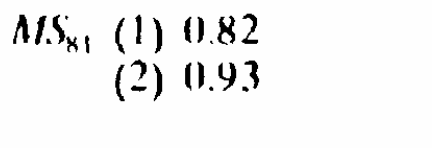 & $\begin{array}{l}0.25 \\
0.09\end{array}$ & $\begin{array}{l}\text { First } \\
\text { indicator } \\
\text { of } M A S=0.08\end{array}$ \\
\hline $\begin{array}{ll}L S_{* 1} & \text { (1) } 0.80 \\
& \text { (2) } 0.81\end{array}$ & $\begin{array}{l}0.33 \\
0.30\end{array}$ & $\begin{array}{l}\text { Second } \\
\text { indicator }\end{array}$ \\
\hline $\begin{aligned} M S_{\mathrm{N}} & (1) 0.95 \\
& (2) 1.0\end{aligned}$ & $\begin{array}{l}0.25 \\
0.0(0)\end{array}$ & of $M A S=-0.01$ \\
\hline $\begin{array}{ll}L . S_{x 1} & \text { (1) } 0.78 \\
& \text { (2) } 0.83\end{array}$ & $\begin{array}{l}0.32 \\
0.30\end{array}$ & $\begin{array}{l}\text { First } \\
\text { indicator } \\
\text { of } L S=0.02\end{array}$ \\
\hline $\begin{array}{r}M / S_{x 5}(1) 0.93 \\
\text { (2) } 0.98\end{array}$ & $\begin{array}{l}0.21 \\
0.09\end{array}$ & $\begin{array}{l}\text { Second } \\
\text { indicator } \\
\text { of } L S=0.05\end{array}$ \\
\hline $\begin{array}{ll}L . S_{K S} & (1) 0.81 \\
& (2) 0.88\end{array}$ & $\begin{array}{l}0.39 \\
0.23\end{array}$ & \\
\hline $\begin{aligned} & M S_{x}>(1) \\
& \text { (2) } 0.97\end{aligned}$ & $\begin{array}{l}0.18 \\
0.07\end{array}$ & \\
\hline $\begin{array}{ll}L S_{x 7} & \text { (1) } 0.85 \\
& \text { (2) } 0.87\end{array}$ & $\begin{array}{l}0.33 \\
0.25\end{array}$ & \\
\hline
\end{tabular}

Loudings for indicurors of exogenous concepts

Sex 1.0*

Age $1.0^{*}$

SES (1) 0.69

(2) 0.68

(3) 0.46

Extraversion (1) 0.66

(2) 0.88

Neuroticism (1) 0.88

(2) 0.85
Error terms of exogenous indicators

0.01

$0 .(0)$

0.52

0.53

0.79

0.56

0.61

0.23

0.27 